\title{
The State Space Modeling of Single, Two and Three ALFC of Power System Using Integral Control and Optimal LQR Control Method
}

\author{
Nilaykumar N. Shah, Chetan D. Kotwal
}

\begin{abstract}
:
The modeling of electric power system on the state space with single, two and three area with integral and optimal control system known as Linear Quadratic Regulator(LQR) for designing the load frequency control system are realized in this paper. The fluctuations on voltage and frequency must be reduced to minimum level against load changes for obtaining high quality electric energy on electric power system. In this paper this is achieved by designing the integral controller and LQR .By using state-space analysis a state equation for three area load frequency is obtained. The proposed optimal LQR load frequency has been compared with integral control Simulink using MATLAB.
\end{abstract}

Keywords: Area Control Error (ACE), Linear Quadratic Regulator (LQR), State Space, Integral Control

\section{INTRODUCTION}

The main purpose of operating the load frequency control is to keep uniform the frequency changes during the load changes. During the power system operation rotor angle, frequency and active power are the main parameters to change [1]. In multi area system a change of power in one area is met by the increase in generation in all areas associated with a change in the tieline power and a reduction in frequency. In the normal operating state the power system demands of areas are satisfied at the nominal frequency. A simple control strategy for the normal mode is to operates in such a way that

1. Keep frequency approximately at nominal value.

2. Maintain the tie-line flow at about schedule.

3. Each area should absorb its own load changes.

Controller must be sensitive against changes in frequency and load. To analyze the control system, the mathematical model must be established. There are two models which are widely used [3],

1. Transfer function model, 2.state variable approach.

In above methods the non-linearity of the system is to be converted in to Linearized system with suitable hypothesis and complete block diagram of the power system is established.

\section{MODELLING OF POWER SYSTEM}

\section{II.1 SINGLE AREA SYSTEM ANALYSIS [2, 3]:}

Fig.1 gives the schematic diagram of load frequency control (p-f) of a turbo-generator. In this control method a frequency sensor senses the change in frequency and gives the signal $\Delta f$. The $\mathrm{p}-\mathrm{f}$ controller senses the change in frequency signal and the increments in tie-line real powers $\Delta P_{\text {tie }}$, which will indirectly provide information about incremental state error. These sensor signals are amplified, mixed and transformed into a real-power control signal $\Delta P_{c}$. The valve control mechanism takes $\Delta P_{c}$ as the input signal and provides the output signal, which will change the position of the inlet valve of the prime mover. [2]

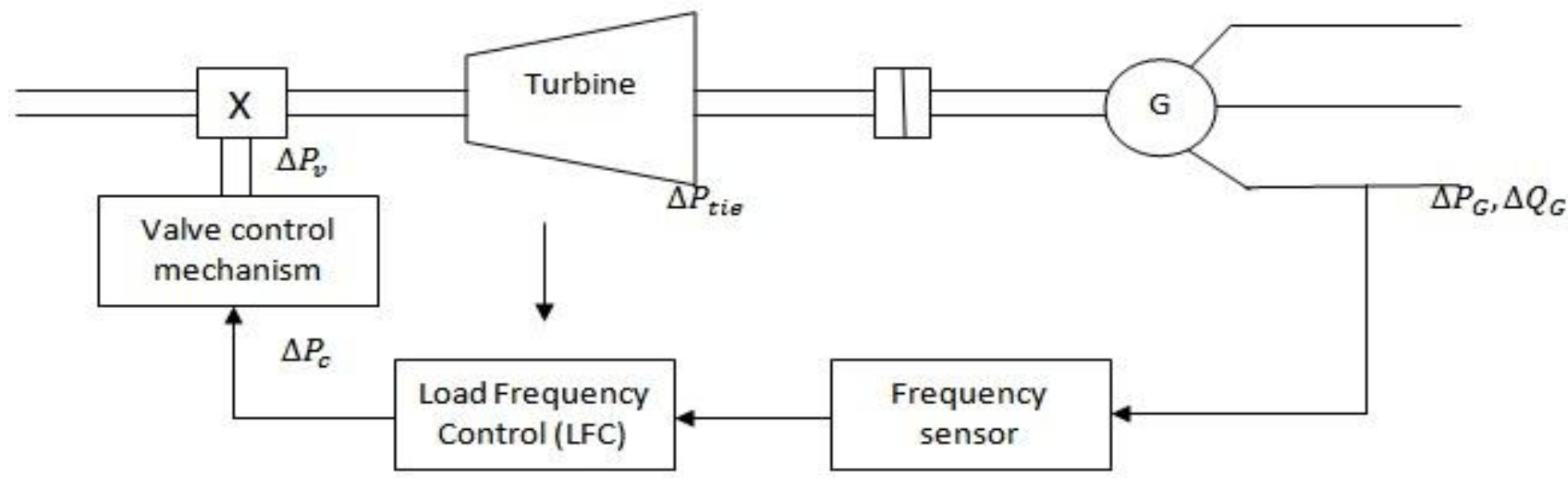

Fig.1 Schematic diagram of $P$-f controller 
From the above Fig.1, the state space equation of single area is developed as under.

$$
\begin{gathered}
\frac{d}{d t}(\Delta \mathrm{f})=\frac{1}{\tau_{p s}}\left[-\Delta f+K_{p s} \Delta P_{G}-K_{p s} \Delta P_{D}\right] \\
\frac{d}{d t}\left(\Delta \mathrm{X}_{\mathrm{E}}\right)=\frac{1}{\tau_{s g}}\left[-\Delta X_{E}+\Delta P_{C}-\Delta f / R\right] \\
\frac{d}{d t}\left(\Delta \mathrm{P}_{\mathrm{G}}\right)=\frac{1}{\tau_{t}}\left[-\Delta P_{G}+\Delta X_{E}\right]
\end{gathered}
$$

From above three equations the state space matrix is obtained as under.

$$
\left[\begin{array}{c}
\Delta \mathrm{X}_{\mathrm{E}} \\
\Delta \mathrm{P}_{\mathrm{G}} \\
\Delta \mathrm{f}
\end{array}\right]=\left[\begin{array}{c}
\dot{X}_{1} \\
\dot{X}_{2} \\
\dot{X}_{3}
\end{array}\right]=\left[\begin{array}{ccc}
-1 / \tau_{s g} & 0 & -\frac{1}{R \tau_{s g}} \\
\frac{1}{\tau_{t}} & -\frac{1}{\tau_{t}} & 0 \\
0 & \frac{K_{p s}}{\tau_{p s}} & -\frac{1}{\tau_{p s}}
\end{array}\right]\left[\begin{array}{l}
x_{1} \\
x_{2} \\
x_{3}
\end{array}\right]+\left[\begin{array}{c}
1 / \tau_{s g} \\
0 \\
0
\end{array}\right] u+\left[\begin{array}{c}
0 \\
0 \\
-\frac{K_{p s}}{\tau_{p s}}
\end{array}\right] \mathrm{p}
$$

In the above matrix $\mathrm{u}$ is system input and $\mathrm{p}$ is the disturbance.

\section{2 TWO AREA SYSTEM ANALYSIS:}

Similarly to the single area modeling, the two area state space equation is developed. [2]

$$
\begin{gathered}
\frac{d}{d t}\left(\Delta \mathrm{f}_{1}\right)=\frac{1}{\tau_{p s 1}}\left[-\Delta f 1+K_{p s 1} \Delta P_{G 1}-K_{p s 1} \Delta P_{D 1}-K_{p s 1} \Delta P_{T L}\right] \\
\frac{d}{d t}\left(\Delta \mathrm{f}_{2}\right)=\frac{1}{\tau_{p s 2}}\left[-\Delta f_{2}+K_{p s 2} \Delta P_{G 2}-K_{p s 2} \Delta P_{D 2}+K_{p s 2} \Delta P_{T L 1}\right] \\
\frac{d}{d t}\left(\Delta \mathrm{X}_{\mathrm{E} 1}\right)=\frac{1}{\tau_{s g 1}}\left[-\Delta X_{E 1}+\Delta P_{C 1}-\Delta f_{1} / R_{1}\right] \\
\frac{d}{d t}\left(\Delta \mathrm{X}_{\mathrm{E} 2}\right)=\frac{1}{\tau_{s g 2}}\left[-\Delta X_{E 2}+\Delta P_{C 2}-\Delta f_{2} / R_{2}\right] \\
\frac{d}{d t}\left(\Delta \mathrm{P}_{\mathrm{G} 1}\right)=\frac{1}{\tau_{t 1}}\left[-\Delta P_{G 1}+\Delta X_{E 1}\right] \\
\frac{d}{d t}\left(\Delta \mathrm{P}_{\mathrm{G} 2}\right)=\frac{1}{\tau_{t 2}}\left[-\Delta P_{G 2}+\Delta X_{E 2}\right] \\
\frac{d}{d t}\left(\Delta \mathrm{P}_{\mathrm{TL} 1}\right)=2 \pi T_{12}^{0}\left[\Delta f_{1}-\Delta f_{2}\right]
\end{gathered}
$$

$$
\left[\begin{array}{c}
\Delta \mathrm{X}_{\mathrm{E} 1} \\
\Delta \mathrm{X}_{\mathrm{E} 2} \\
\Delta \mathrm{P}_{\mathrm{G} 1} \\
\Delta \mathrm{P}_{\mathrm{G} 2} \\
\Delta \mathrm{f}_{1} \\
\Delta \mathrm{f}_{2} \\
\Delta \mathrm{P}_{\mathrm{TL} 1}
\end{array}\right]=\left[\begin{array}{c}
\dot{x_{1}} \\
\dot{\dot{x}_{2}} \\
\dot{x_{3}} \\
\dot{x_{4}} \\
\dot{\dot{x}_{5}} \\
\dot{\dot{x}_{6}} \\
\dot{x_{7}}
\end{array}\right]=\left[\begin{array}{ccccccc}
-\frac{1}{\tau_{p s 1}} & 0 & 0 & 0 & \frac{K_{p s 1}}{\tau_{p s 1}} & 0 & -\frac{K_{p s 1}}{\tau_{p s 1}} \\
0 & -1 / \tau_{p s 2} & 0 & 0 & 0 & \frac{K_{p s 2}}{\tau_{p s 2}} & \frac{K_{p s 2}}{\tau_{p s 2} 2} \\
\frac{1}{R_{1} \tau_{s g 1}} & 0 & -1 / \tau_{s g 1} & 0 & 0 & 0 & 0 \\
0 & -1 / R_{2} \tau_{s g 2} & 0 & -1 / \tau_{s g 2} & 0 & 0 & 0 \\
0 & 0 & 1 / \tau_{t 1} & 0 & -1 / \tau_{t 1} & 0 & 0 \\
0 & 0 & 0 & 1 / \tau_{t 2} & 0 & -1 / \tau_{t 2} & 0 \\
2 \pi T_{12}^{0} & -2 \pi T_{12}^{0} & 0 & 0 & 0 & 0 & 0
\end{array}\right]\left[\begin{array}{l}
x_{1} \\
x_{2} \\
x_{3} \\
x_{4} \\
x_{5} \\
x_{6} \\
x_{7}
\end{array}\right]+
$$




$$
\left[\begin{array}{cc}
0 & 0 \\
0 & 0 \\
1 / \tau_{s g 1} & 0 \\
0 & 1 / \tau_{s g 2} \\
0 & 0 \\
0 & 0 \\
0 & 0
\end{array}\right]\left[\begin{array}{l}
u_{1} \\
u_{2}
\end{array}\right]+\left[\begin{array}{cc}
-\frac{K_{p s 1}}{\tau_{p s 1}} & 0 \\
0 & -K_{p s 2} / \tau_{p s 2} \\
0 & 0 \\
0 & 0 \\
0 & 0 \\
0 & 0 \\
0 & 0
\end{array}\right]\left[\begin{array}{l}
p_{1} \\
p_{2}
\end{array}\right]
$$

\section{II.3 THREE AREA SYSTEM ANALYSIS:}

Similarly to the two area modeling, the three area state space equation is developed as under [2].

$$
\begin{aligned}
& \frac{d}{d t}\left(\Delta \mathrm{f}_{1}\right)=\frac{1}{\tau_{p s 1}}\left[-\Delta f 1+K_{p s 1} \Delta P_{G 1}-K_{p s 1} \Delta P_{D 1}-K_{p s 1} \Delta P_{T L 1}\right] \\
& \frac{d}{d t}\left(\Delta \mathrm{f}_{2}\right)=\frac{1}{\tau_{p s 2}}\left[-\Delta f_{2}+K_{p s 2} \Delta P_{G 2}-K_{p s 2} \Delta P_{D 2}-K_{p s 2} \Delta P_{T L 2}\right] \\
& \frac{d}{d t}\left(\Delta \mathrm{f}_{3}\right)=\frac{1}{\tau_{p s 3}}\left[-\Delta f_{3}+K_{p s 3} \Delta P_{G 3}-K_{p s 3} \Delta P_{D 3}-K_{p s 3} \Delta P_{T L 3}\right] \\
& \frac{d}{d t}\left(\Delta \mathrm{X}_{\mathrm{E} 1}\right)=\frac{1}{\tau_{s g 1}}\left[-\Delta X_{E 1}+\Delta P_{C 1}-\Delta f_{1} / R_{1}\right] \\
& \frac{d}{d t}\left(\Delta \mathrm{X}_{\mathrm{E} 2}\right)=\frac{1}{\tau_{s g 2}}\left[-\Delta X_{E 2}+\Delta P_{C 2}-\Delta f_{2} / R_{2}\right] \\
& \frac{d}{d t}\left(\Delta \mathrm{X}_{\mathrm{E} 3}\right)=\frac{1}{\tau_{s g 3}}\left[-\Delta X_{E 3}+\Delta P_{C 3}-\Delta f_{3} / R_{3}\right] \\
& \frac{d}{d t}\left(\Delta \mathrm{P}_{\mathrm{G} 1}\right)=\frac{1}{\tau_{t 1}}\left[-\Delta P_{G 1}+\Delta X_{E 1}\right] \\
& \frac{d}{d t}\left(\Delta \mathrm{P}_{\mathrm{G} 2}\right)=\frac{1}{\tau_{t 2}}\left[-\Delta P_{G 2}+\Delta X_{E 2}\right] \\
& \frac{d}{d t}\left(\Delta \mathrm{P}_{\mathrm{G} 3}\right)=\frac{1}{\tau_{t 3}}\left[-\Delta P_{G 3}+\Delta X_{E 3}\right] \\
& \frac{d}{d t}\left(\Delta \mathrm{P}_{\mathrm{TL} 1}\right)=2 \pi T_{12}^{0}\left[\Delta f_{1}-\Delta f_{2}\right]+2 \pi T_{13}^{0}\left[\Delta f_{1}-\Delta f_{3}\right] \\
& \frac{d}{d t}\left(\Delta \mathrm{P}_{\mathrm{TL} 2}\right)=2 \pi T_{12}^{0}\left[\Delta f_{1}-\Delta f_{2}\right]-2 \pi T_{23}^{0}\left[\Delta f_{2}-\Delta f_{3}\right] \\
& \frac{d}{d t}\left(\Delta \mathrm{P}_{\mathrm{TL} 3}\right)=2 \pi T_{13}^{0}\left[\Delta f_{1}-\Delta f_{3}\right]+2 \pi T_{23}^{0}\left[\Delta f_{2}-\Delta f_{3}\right] \\
& {\left[\begin{array}{c}
\Delta \mathrm{X}_{\mathrm{E} 1} \\
\Delta \mathrm{X}_{\mathrm{E} 2} \\
\Delta \mathrm{X}_{\mathrm{E} 3} \\
\Delta \mathrm{P}_{\mathrm{G} 1} \\
\Delta \mathrm{P}_{\mathrm{G} 2} \\
\Delta \mathrm{P}_{\mathrm{G} 3} \\
\Delta \mathrm{f}_{1} \\
\Delta \mathrm{f}_{2} \\
\Delta \mathrm{f}_{3} \\
\Delta \mathrm{P}_{\mathrm{TL} 1} \\
\Delta \mathrm{P}_{\mathrm{TL} 2} \\
\Delta \mathrm{P}_{\mathrm{TL} 3}
\end{array}\right]=\left[\begin{array}{c}
\dot{x_{1}} \\
\dot{x_{2}} \\
\dot{x_{3}} \\
\dot{x_{4}} \\
\dot{x_{5}} \\
\dot{x_{6}} \\
\dot{x_{7}} \\
\dot{x_{8}} \\
\dot{x_{9}} \\
\dot{x_{10}} \\
\dot{x_{11}} \\
\dot{x_{12}}
\end{array}\right]=}
\end{aligned}
$$




$\left[\begin{array}{cccccccccccc}-\frac{1}{\tau_{p s 1}} & 0 & 0 & 0 & 0 & 0 & \frac{K_{p s 1}}{\tau_{p s 1}} & 0 & 0 & -\frac{K_{p s 1}}{\tau_{p s 1}} & 0 & 0 \\ 0 & \frac{-1}{\tau_{p s 2}} & 0 & 0 & 0 & 0 & 0 & \frac{K_{p s 1}}{\tau_{p s 1}} & 0 & 0 & -\frac{K_{p s 1}}{\tau_{p s 1}} & 0 \\ 0 & 0 & \frac{-1}{\tau_{p s 2}} & 0 & 0 & 0 & 0 & 0 & \frac{K_{p s 1}}{\tau_{p s 1}} & 0 & 0 & -\frac{K_{p s 1}}{\tau_{p s 1}} \\ -\frac{-1}{R_{1} \tau_{g s 1}} & 0 & 0 & \frac{-1}{\tau_{s g 1}} & 0 & 0 & 0 & 0 & 0 & 0 & 0 & 0 \\ 0 & -\frac{1}{R_{2} \tau_{g s 2}} & 0 & 0 & \frac{-1}{\tau_{s g 1}} & 0 & 0 & 0 & 0 & 0 & 0 & 0 \\ 0 & 0 & -\frac{1}{R_{2} \tau_{g s 3}} & 0 & 0 & \frac{-1}{\tau_{s g 3}} & 0 & 0 & 0 & 0 & 0 & 0 \\ 0 & 0 & 0 & \frac{1}{\tau_{t 1}} & 0 & 0 & -\frac{1}{\tau_{t 1}} & 0 & 0 & 0 & 0 & 0 \\ 0 & 0 & 0 & 0 & \frac{1}{\tau_{t 2}} & 0 & 0 & -\frac{1}{\tau_{t 2}} & 0 & 0 & 0 & 0 \\ 0 & 0 & 0 & 0 & 0 & \frac{1}{\tau_{t 3}} & 0 & 0 & -\frac{1}{\tau_{t 3}} & 0 & 0 & 0 \\ 2 \pi\left(T_{12}^{0}+T_{13}^{0}\right) & -2 \pi T_{12}^{0} & -2 \pi T_{13}^{0} & 0 & 0 & 0 & 0 & 0 & 0 & 0 & 0 & 0 \\ 2 \pi T_{12}^{0} & -2 \pi\left(T_{12}^{0}+T_{23}^{0}\right) & 2 \pi T_{23}^{0} & 0 & 0 & 0 & 0 & 0 & 0 & 0 & 0 & 0 \\ 2 \pi T_{13}^{0} & 2 \pi T_{23}^{0} & -2 \pi\left(T_{13}^{0}+T_{23}^{0}\right) & 0 & 0 & 0 & 0 & 0 & 0 & 0 & 0 & 0\end{array}\right]$

$$
[B]=\left[\begin{array}{ccc}
0 & 0 & 0 \\
0 & 0 & 0 \\
0 & 0 & 0 \\
1 / \tau_{s g 1} & 0 & 0 \\
0 & 1 / \tau_{s g 2} & 0 \\
0 & 0 & 1 / \tau_{s g 3} \\
0 & 0 & 0 \\
0 & 0 & 0 \\
0 & 0 & 0 \\
0 & 0 & 0 \\
0 & 0 & 0 \\
0 & 0 & 0
\end{array}\right] \quad[J]=\left[\begin{array}{ccc}
-\frac{K_{p s 1}}{\tau_{p s 1}} & 0 & 0 \\
0 & -\frac{K_{p s 2}}{\tau_{p s 2}} & 0 \\
0 & 0 & -\frac{K_{p s 3}}{\tau_{p s 3}} \\
0 & 0 & 0 \\
0 & 0 & 0 \\
0 & 0 & 0 \\
0 & 0 & 0 \\
0 & 0 & 0 \\
0 & 0 & 0 \\
0 & 0 & 0 \\
0 & 0 & 0 \\
0 & 0 & 0
\end{array}\right]
$$

III. INTEGRAL CONTROL [2]

The integral control is composed of a frequency sensor and an integrator. The frequency sensor measures the frequency error $\Delta \mathrm{f}$ and this error signal is fed into the integrator. The input to the integrator is called the Area Control Error (ACE). The ACE is the change in area frequency, which when used in an integral-control loop, forces the steady-state frequency error to zero. Fig. 2 shows the proportional plus integral control of LFC of a single-area system.

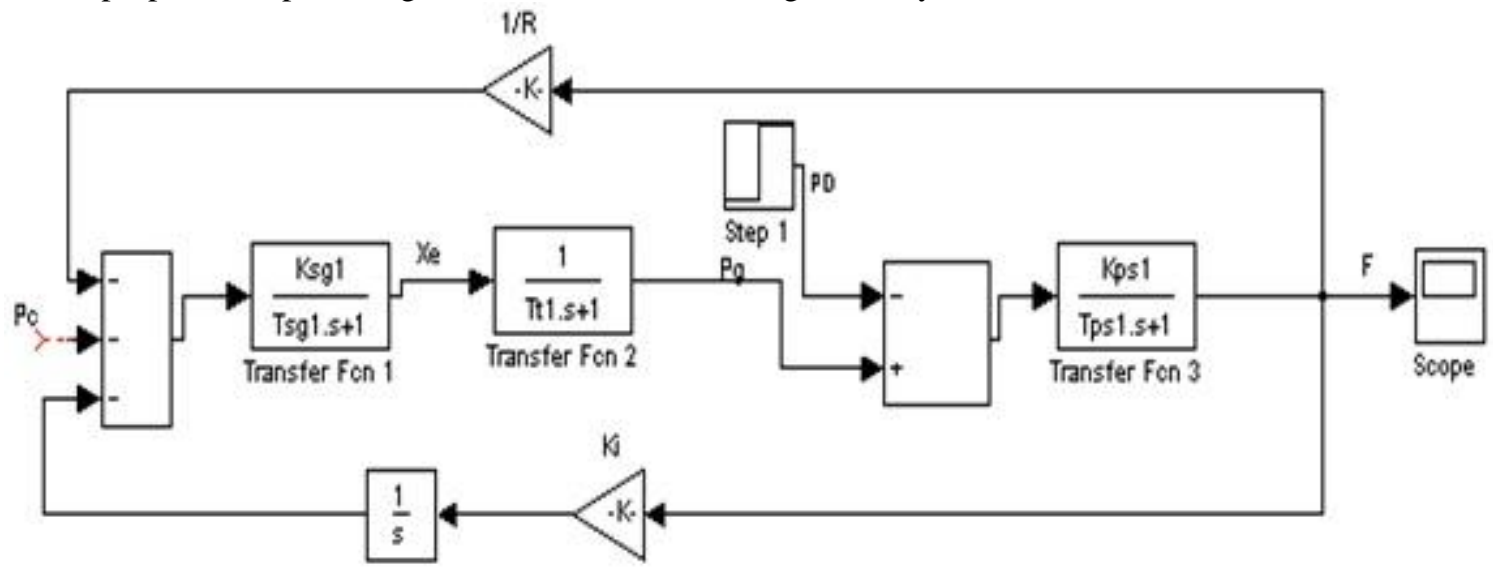

Fig.2 PI control of LFC of a single- area system. 
IOSR Journal of Engineering

Mar. 2012, Vol. 2(3) pp: 501-510

The integrator produces a real-power command signal $\Delta \mathrm{Pc}$ and is given by

$$
\begin{aligned}
& \Delta \mathrm{Pc}=-\mathrm{Ki} \int \Delta f d t \\
= & -\mathrm{Ki} \int(A C E) d t
\end{aligned}
$$

$\Delta \mathrm{Pc}=$ input of speed - changer

$\mathrm{Ki}=$ integral gain constant.

The value of $\mathrm{Ki}$ is given by below equation. [4]

$$
\mathrm{K}_{\mathrm{i}}=1 / 4 \tau_{p} K_{p s}\left(1+\frac{K p s}{R}\right)^{2}=\mathrm{K}_{\mathrm{crit}}
$$

The value of $\mathrm{Ki}$ is so selected that the response will be damped and non-oscillatory. In this case

$$
\mathrm{K}_{\mathrm{i}}<K_{\text {crit }} \text {. }
$$

In our analysis the $\mathrm{K}_{\mathrm{i}}$ is selected by above equation. It increases the system type by 1 which forces the final frequency deviation to zero.

\section{OPTIMAL CONTROL DESIGN FOR THE LOAD FREQUENCY CONTROL AGAINTST TO LOAD CHANGES. $[1,3,5,6]$}

Optimal control is a branch of modern control theory that deals with designing controls for dynamic systems by minimizing a performance index that depends on the system variables.

Consider the plant described by

$$
\dot{X}=A x(t)+B u(t)
$$

The problem is to find the vector $\mathrm{K}(\mathrm{t})$ of the control law

$$
u(t)=-K(t) x(t)
$$

This minimizes the value of a quadratic performance index $\mathbf{J}$ of the form

$$
J=\int_{t_{0}}^{t_{f}}\left(x^{\prime} Q x+u^{\prime} R u\right) d t
$$

The constraint problem is solved by using an n-vector of Lagrange multipliers, $\lambda$. The problem reduces to the minimization of the following unconstrained function.

$$
\alpha(x, \lambda, u, t)=\left[x^{\prime} Q x+u^{\prime} R u\right]+\lambda^{\prime}[A x+B u-\dot{x}]
$$

The optimal values (denoted by subscript $*$ ) are found by equating the partial derivatives to zero.

$$
\begin{array}{ccc}
\frac{\partial £ \mathcal{L}}{\partial \lambda}=A X^{*}+B u^{*}-\dot{x}=0 & \Rightarrow & \dot{x}^{*}=A X^{*}+B u^{*} \\
\frac{\partial £ \mathcal{L}}{\partial u}=2 R u^{*}+\lambda^{\prime} B=0 & \Rightarrow & u^{*}=-\frac{1}{2} R^{-1} \lambda^{\prime} B \\
\frac{\partial £ \mathcal{d}}{\partial x}=2 x^{\prime *} Q+\dot{\lambda}^{\prime}+\lambda^{\prime} A=0 & \Rightarrow & \dot{\lambda}=-2 Q x^{*}-A^{\prime} \lambda
\end{array}
$$

Assume that there exists a symmetric, time varying positive definite matrix $\mathrm{p}(\mathrm{t})$ satisfying

$$
\lambda=2 p(t) x^{*}
$$

Obtaining derivative of above equation

$$
\lambda=2\left(\dot{p} \dot{x}^{*}+p \dot{x}^{*}\right)
$$

Substituting values gives the optimal closed-loop control law

$$
u^{*}(t)=-R^{-1} B^{\prime} p(t) x^{*}
$$


IOSR Journal of Engineering

Mar. 2012, Vol. 2(3) pp: 501-510

Finally equating, we obtain

$$
\dot{p}(t)=-p(t) A-A^{\prime} p(t)-Q+p(t) B R^{-1} B^{\prime} p(t)
$$

For linear time-invariant systems, since $\dot{p}=0$, when the process is of infinite duration, that ist $t_{f}=\infty$, equation reduces to the algebraic Riccati equation

$$
p A+A^{\prime} p+Q-p B R^{-1} B^{\prime} p=0
$$

In solution of the above equation, Riccati equation solution is used. From Riccati equation matrix optimal feed-back gaining and state response of the system at the beginning are solved. For the solution of Riccati equation, [k, p] = lqr $(\mathrm{A}, \mathrm{B}, \mathrm{Q}, \mathrm{R})$ function in Mat lab Control Toolbox is used.

In ( The modeling of electric power system on the state space and controlling of optimal LQR load frequency), journal of electrical and electronics engineering 2009,volume 9, number 2 preferred Q and R parameters to design the optimal LQR. [7] Using the Riccati equations, $\mathrm{K}$ feed-back gaining matrix is selected. If the system response is not stable, the new $\mathrm{Q}$ and $\mathrm{R}$ weight matrices are determined.

\section{RESULTS}

By using MATLAB Simulink software following results are obtained for single area, two area and three area systems. All the three types of system are tested for different operating conditions which includes 1) without any change in the load, 2) with the change in load, 3) with ACE controller and 4) with LQR controller. For more than one system the performance is observed for the same systems or with different systems.

\section{V.1 SINGLE AREA SYSTEM:}

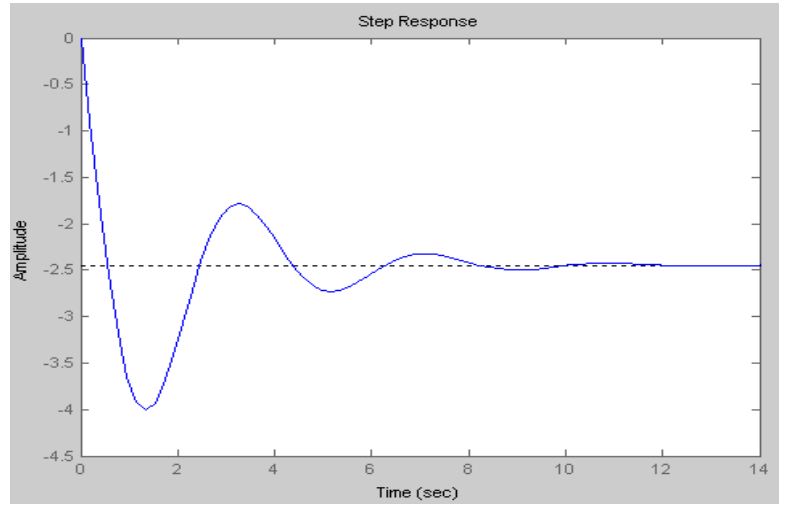

Fig.5.1.1. WITHOUT LOAD CHANGE

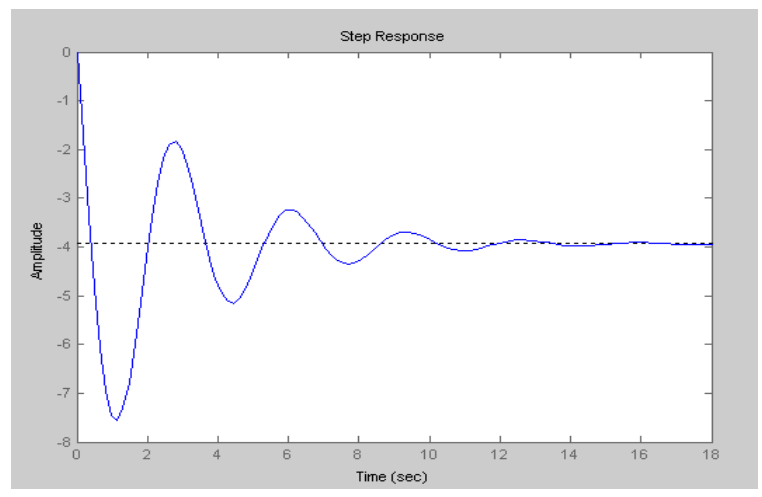

Fig.5.1.3. WITH ACE CONTROLLER

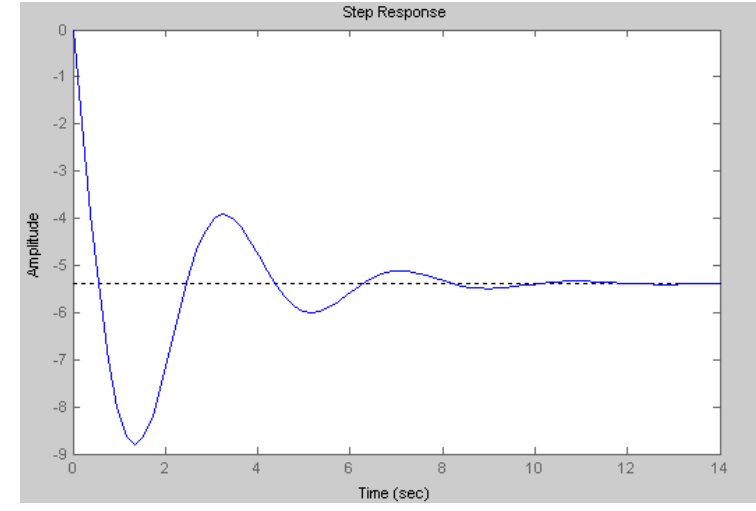

Fig.5.1.2. LOAD CHANGE

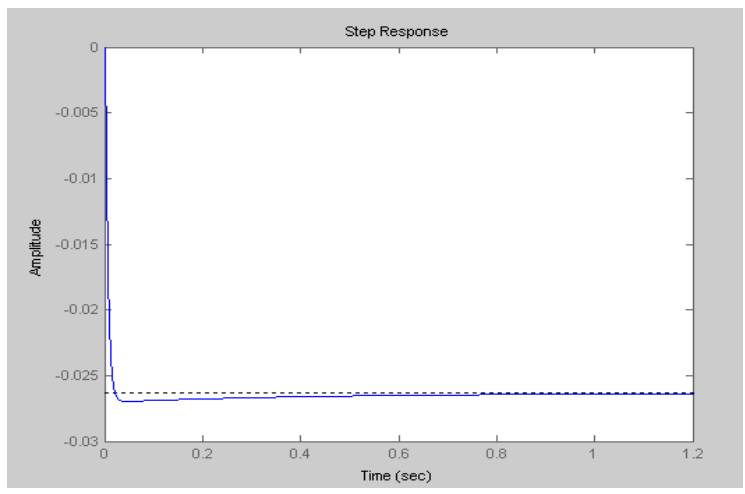

Fig5.1.4. WITH LQR CONTROLLER 


\section{V.2. TWO AREA SYSTEM:}

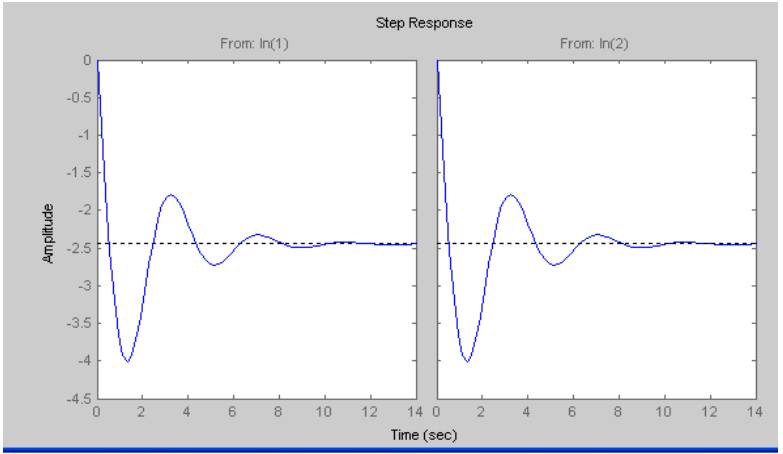

Fig.5.2.1TWO SAME SYSTEMS WITHOUT LOAD CHANGE

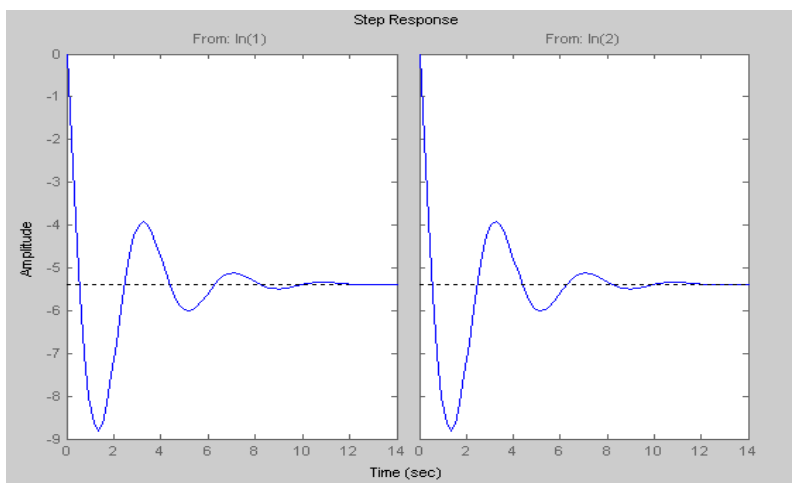

Fig.5.2.3TWO SAME SYSTEMS WITH LOAD CHANGE

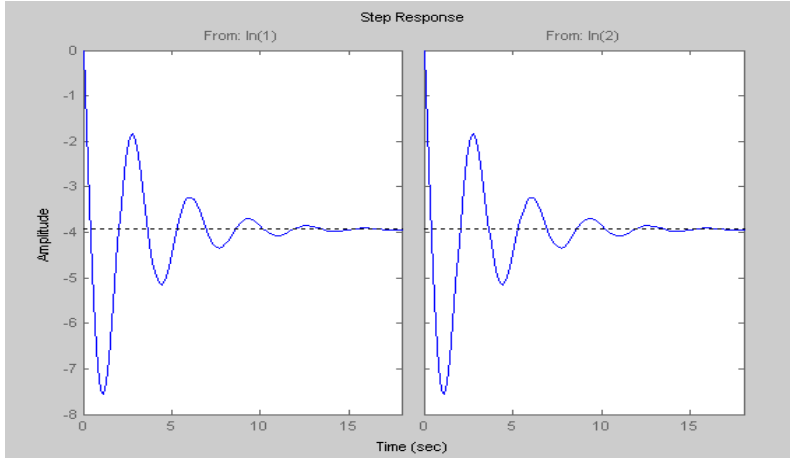

Fig.5.2.5TWO SAME SYSTEMS WITH ACE

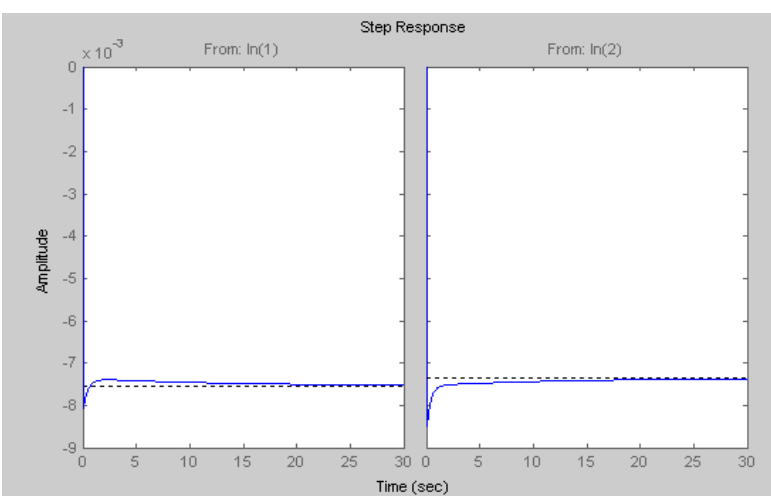

Fig.5.2.7 TWO SAME SYSTEMS WITH LQR

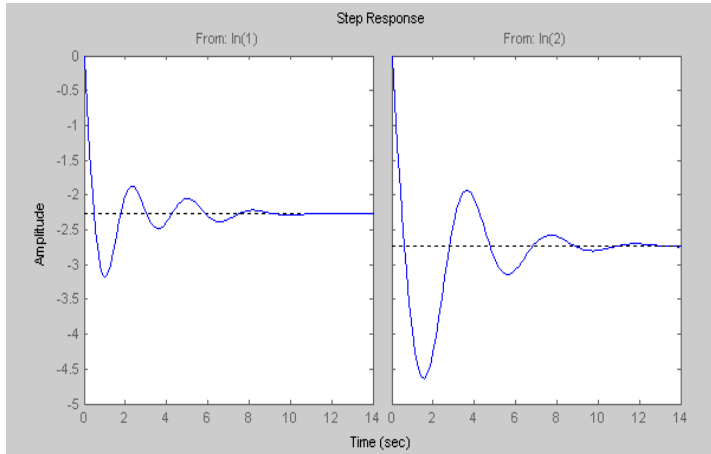

Fig.5.2.2 TWO DIFFERENT SYSTEMS WITHOUT LOAD CHANGE

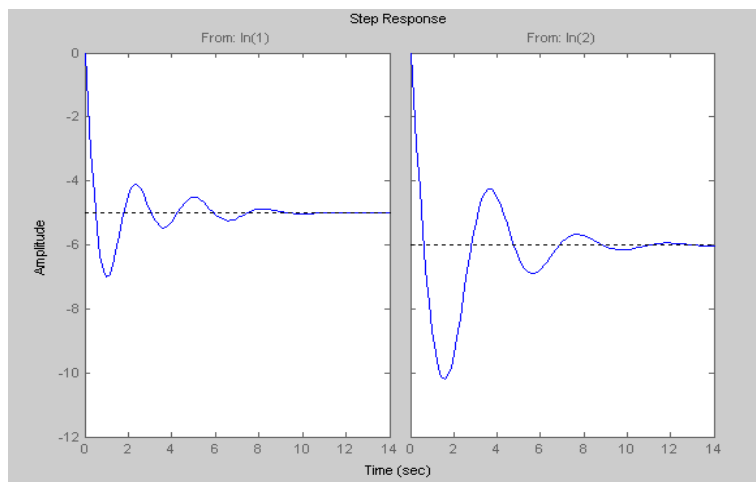

Fig.5.2.4 TWO DIFFERENT SYSTEMS WITH LOAD CHANGE

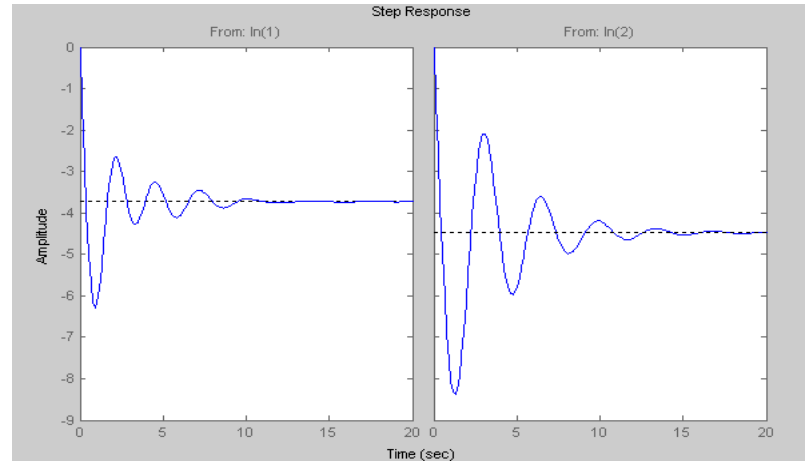

Fig.5.2.6TWO DIFFERENT SYSTEMS WITH ACE

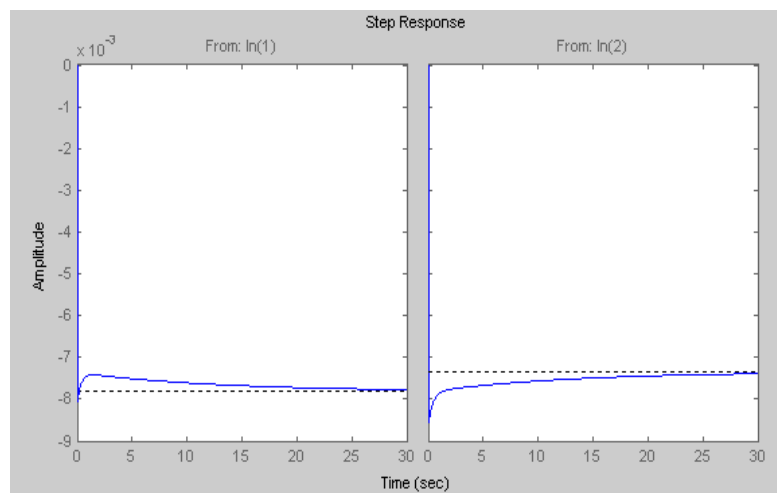

Fig5.2.8 TWO DIFFERENT SYSTEMS WITH LQR 


\section{V.3. THREE AREA SYSTEM:}

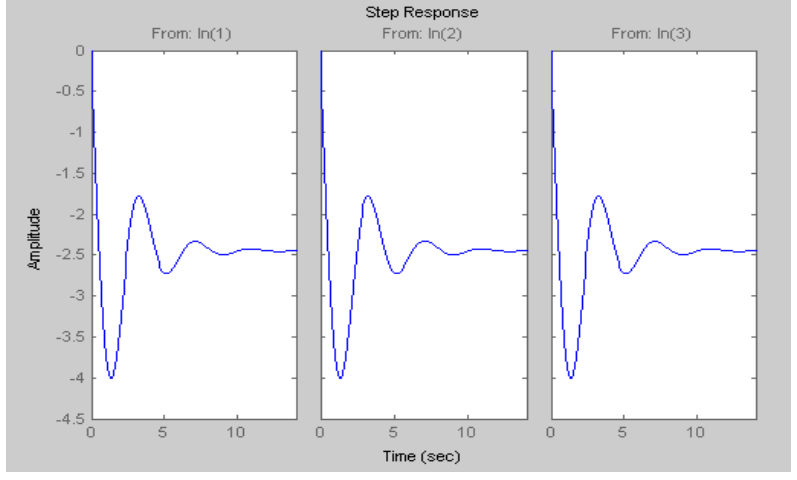

Fig.5.3.1 THREE SAME SYSTEMS WITHOUT LOAD CHANGE

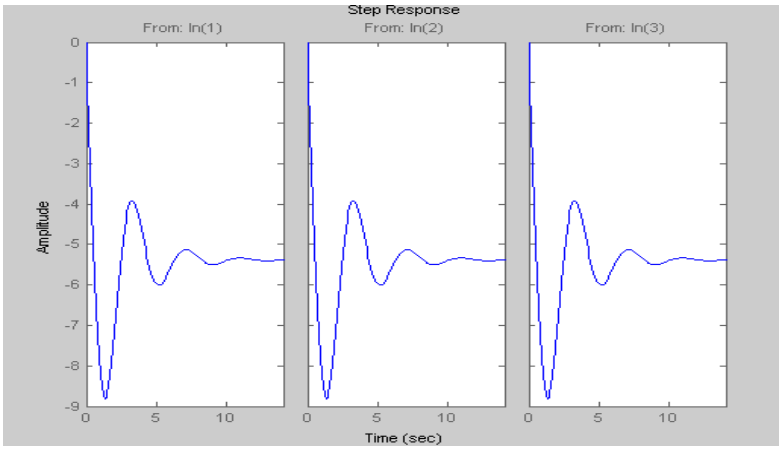

Fig.5.3.3THREE SAME SYSTEMS WITH LOAD CHANGE

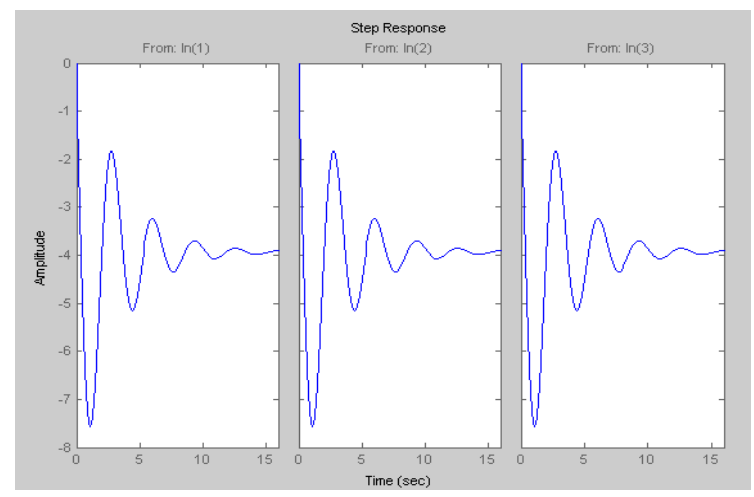

Fig.5.3.5THREE SAME SYSTEMS WITH ACE

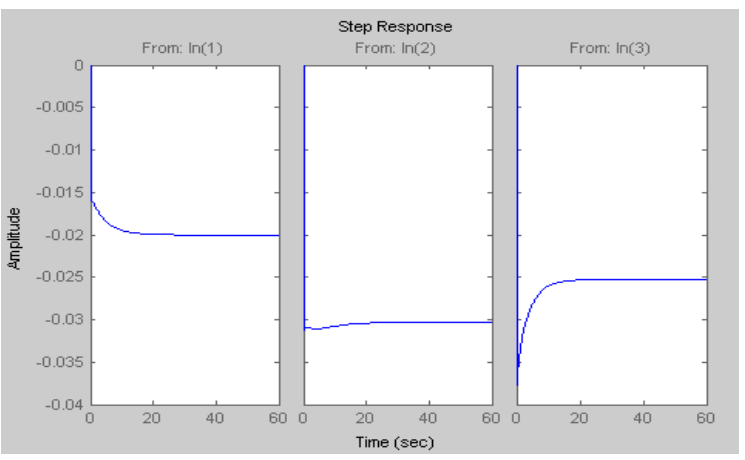

Fig.5.3.7 THREE SAME SYSTEMS WITH LQR

ISSN: 2250-3021

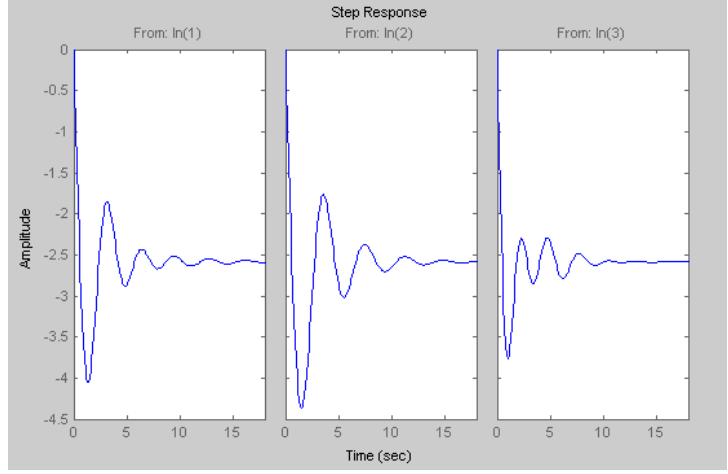

Fig.5.3.2 THREE SAME SYSTEMS WITHOUT LOAD CHANGE

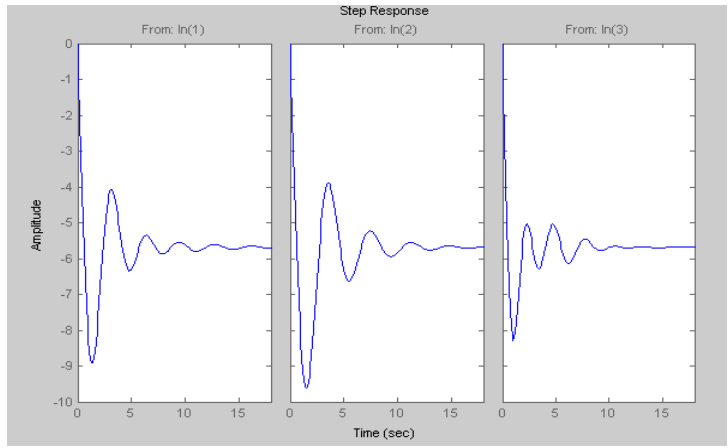

Fig.5.3.4 THREE DIFFERENT SYSTEMS S WITH LOAD CHANGE

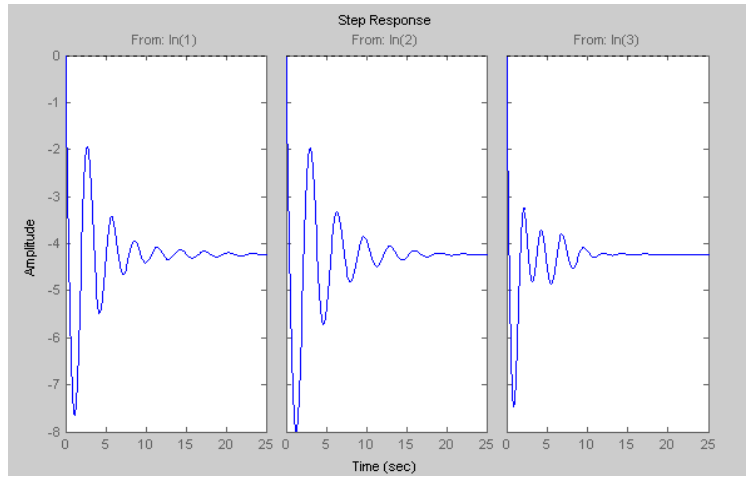

Fig.5.3.6THREE DIFFERENT SYSTEMS WITH ACE

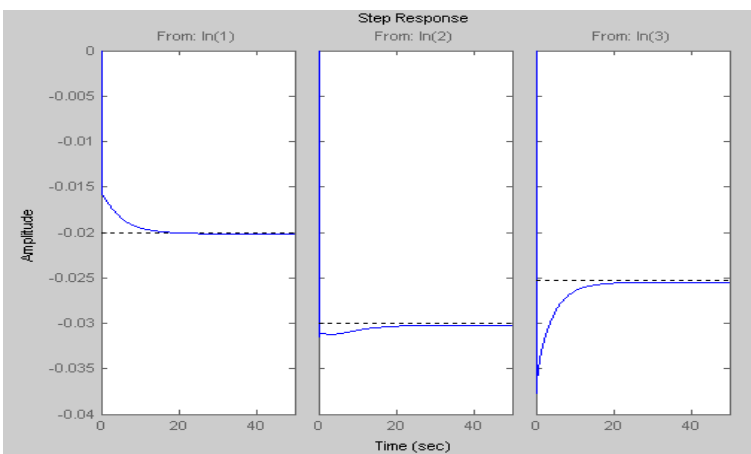

Fig.5.3.8 THREE DIFFERENT SYSTEMS WITH LQR www.iosrjen.org 
VI. DISCUSSION

From the above results the frequency deviation of all the areas is given in the below TABLE I.

\begin{tabular}{|c|c|c|c|c|c|}
\hline EFFECTS & SINGLE AREA & $\begin{array}{c}\text { TWO AREA } \\
\text { SAME SYSTEM }\end{array}$ & $\begin{array}{c}\text { TWO AREA } \\
\text { DIFFERENT } \\
\text { SYSTEM }\end{array}$ & $\begin{array}{l}\text { THREE AREA } \\
\text { SAME SYSTEM }\end{array}$ & $\begin{array}{l}\text { THREE AREA } \\
\text { DIFFERENT } \\
\text { SYSTEM }\end{array}$ \\
\hline $\begin{array}{l}\text { WITHOUT LOAD } \\
\text { CHANGE }\end{array}$ & $\begin{array}{c}\mathbf{- 2 . 4 5} \\
\text { ( see Fig.5.1.1) }\end{array}$ & $\begin{array}{c}\mathbf{- 2 . 4 5} \\
(\text { see Fig.5.2.1) }\end{array}$ & $\begin{array}{c}\mathbf{- 2 . 4 5} \\
\text { ( seeFig.5.2.2) }\end{array}$ & $\begin{array}{c}\mathbf{- 2 . 4 8} \\
\text { ( seeFig.5.3.1) }\end{array}$ & $\begin{array}{c}\mathbf{- 2 . 5 8} \\
\text { ( see Fig.5.3.2) }\end{array}$ \\
\hline LOAD CHANGE & $\begin{array}{c}\mathbf{- 5 . 4} \\
\text { ( see Fig.5.1.2) }\end{array}$ & $\begin{array}{c}\mathbf{- 5 . 6} \\
\text { ( see Fig.5.2.3) }\end{array}$ & $\begin{array}{c}\mathbf{- 5 . 9 9} \\
\text { ( see Fig.5.2.4) }\end{array}$ & $\begin{array}{c}\mathbf{- 5 . 0 .} \\
\text { ( see Fig.5.3.3) }\end{array}$ & $\begin{array}{c}\mathbf{- 5 . 7 9} \\
\text { ( see Fig.5.3.4) }\end{array}$ \\
\hline $\begin{array}{l}\text { ACE } \\
\text { CONTROLLER- }\end{array}$ & $\begin{array}{c}\text {-3.91 } \\
\text { (see Fig.5.1.3) }\end{array}$ & $\begin{array}{c}\mathbf{- 3 . 9 4} \\
(\text { see Fig.5.2.5) }\end{array}$ & $\begin{array}{c}-\mathbf{- 4 . 4 9} \\
\text { ( see Fig.5.2.6) }\end{array}$ & $\begin{array}{c}\mathbf{- 3 . 9 3} \\
(\text { see Fig.5.3.5) }\end{array}$ & $\begin{array}{c}-\mathbf{- 4 . 2 3} \\
\text { ( see Fig.5.3.6) }\end{array}$ \\
\hline $\begin{array}{l}\text { LQR } \\
\text { CONTROLLER- }\end{array}$ & $\begin{array}{c}\mathbf{- 0 . 0 2 6 5} \\
\text { (see Fig 5.1.4) }\end{array}$ & $\begin{array}{c}\mathbf{- 0 . 0 8 2 6} \\
(\text { see Fig.5.2.7) }\end{array}$ & $\begin{array}{c}\mathbf{- 0 . 0 8 9 6} \\
\text { ( see Fig.5.2.8) }\end{array}$ & $\begin{array}{c}\mathbf{- 0 . 0 1 9 9} \\
\text { ( see fig.5.3.7) } \\
\end{array}$ & $\begin{array}{c}\mathbf{- 0 . 0 3 0 3} \\
(\text { see Fig.5.3.8) }\end{array}$ \\
\hline
\end{tabular}

It is seen from the above table that as the area is increased with the same system the frequency deviation is increased little bit. And for different system its deviation is again increased. The deviation is controlled by ACE controller up to minor value its affect on areas and system is taken. In case of LQR controller, as the load is changed the frequency according to the controller with load placement becomes stable in a short time. The load frequency is not affected much with the changes in the system parameter. Results are more satisfied in LQR controller.

\section{CONCLUSION}

In this study the ACE controller and optimal LQR controller is implemented as supplementary controller in each area of a three are interconnected power system for the cases with and without load changes. The positive effects of LQR controller is shown in all cases of different areas. Results of all the cases are compared. It shows the improved dynamic response of LQR controller compared to the conventional ACE controller. LQR design procedure is simpler and clearer than the traditional control design. With this high quality and performance controller, no modification is made in the controller structure against to changing parameters and loads. This demonstrates us that optimal LQR controller is more robust against changes that occur in the system than the other traditional controllers.

\section{APPENDIX}

\begin{tabular}{|l|l|l|l|}
\hline PARAMETERS & SYSTEM 1 & SYSTEM 2 & SYSTEM 3 \\
\hline Power system gain constant, $K_{p s}$ & 105 & 120 & 100 \\
\hline Power system time constant, $\tau_{p s}$ & 22 & 20 & 22 \\
\hline Speed Regulation R & 2.5 & 2.5 & 3 \\
\hline Normal frequency, f & 50 & 50 & 50 \\
\hline Governor time constant, $\tau_{s g}$ & 0.3 & 0.2 & 0.3 \\
\hline Turbine time constant, $\tau_{t}$ & 0.5 & 0.4 & 0.5 \\
\hline $\begin{array}{l}\text { Integration time, constant, } \mathrm{Ki}, \\
\mathrm{K}_{\mathrm{i}}=1 / 4 \tau_{p} K_{p s}\left(1+\frac{K p s}{R}\right)^{2}=\mathrm{K}_{\mathrm{crit}}\end{array}$ & 0.15 & 0.1 & 0.15 \\
\hline $\mathrm{T} 12=0.08, \mathrm{~T} 23=0.08$ and T13 $=0.07$. \\
\hline$\Delta \mathrm{X}_{\mathrm{E}}=$ Change in valve position. \\
\hline \multicolumn{3}{|c|}{$\Delta \mathrm{f}=$ Change in generation. } \\
\hline$\Delta \mathrm{P}_{\mathrm{TL}}=$ Change in fie - line power. \\
\hline
\end{tabular}


[1] Hadi Sadat, "Power System Analysis", 2 Edition Tata McGraw Hill, India

[2] S. Sivanagaraju, G Sreenivasan, "Power System Operation and Control”, Pearson India.

[3] Adman Kakilli, Yuksel Oguz, Huseyin Calik, "The Modeling Of Electric Power Systems on The State Space and Controlling Of Optimal LQR Load Frequency" , Journal of Electrical and Electronics Engineering 2009, Vol. 9, Number 2.

[4] Sathans, Akhilesh Swarup, “Automatic Generation Control of Two Area Power System with and Without SMES: From Conventional To Modern and Intelligent Control", International Journal of Engineering Science and Technology (IJEST), Vol.3 No. 5 May 2011.

[5] K.P.Singh Parmar, S.Majhi, D.P.Khothari, "Optimal load frequency control of an interconnected power system", MIT International Journal of Electrical and Instrument Engg, Vol-1, No.1, Jan-2011.

[6] Mariano, S.J.P. Ferreira L.A.F.M., “Optimal control Load frequency control of a large power system", Power Electronics and Motion control conference 2008.

[7] M. Aldeen and H. Trinh, "Load frequency control of interconnected power systems via constrained feedback control schemes”, Int. Journal Computing Elect Eng Vol. 20 (1) (1994), pp. 71-88.

[8] K.P. Singh Parmar, S. Majhi and D. P. Kothari, "Multi-Area Load Frequency Control in a Power System Using Optimal Output Feedback Method”, IEEE Conf. proceedings, PEDES 2010 New Delhi, India.

[9] P. Kundur, "Power System Stability \& Control”, Tata McGraw Hill, New Delhi, Fifth reprint 2008, pp. 581-626.

[10] C.E. Fosha and O.I. Elgerd, "The megawatt frequency control problem: a new approach via optimal control theory", IEEE Trans. Power Appl. System, 89 (4) (1970), pp. 563-577.

Chetan D. Kotwal received his M.E. degree from M.S.University of Baroda, Baroda, India in 1997.From 1999 he has been a faculty member of Electrical Engineering in Sardar Vallabhbhai Patel Institute of Technology, Vasad, Gujarat, India. He is PhD in Electrical Engineering from IIT Roorkee, India. His areas of interests are in Power Electronics applications to Power System, FACTS controllers, Power System Dynamics, Evolutionary Algorithms, Smart Grid.

Nilaykumar N. Shah received his M.E. degree from S.P.University of VVNAGAR, Anand, India in 2002. From 2002 he has been a faculty member of Electrical Engineering in Sardar Vallabhbhai Patel Institute of Technology, Vasad, Gujarat, India. His areas of interests are in Power System, Deregulation of electricity market, Power System Operation and Control, AI applications to power system. 